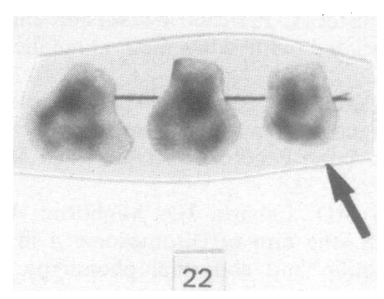

FIG 2 Partial karyotype of the patient with a supernumerary chromosome smaller than a $G$ chromosome.

carries three or four copies of D22S9 mapping at $22 \mathrm{q} 11 .{ }^{1}$

In this paper we report a male infant with the characteristic phenotype of the cat eye syndrome, who also had aganglionosis of the small and large intestine.

\section{Case report}

This was a newborn male infant born after 38 weeks' gestation by caesarean section. His Apgar score was 8 and 9 . He was the fourth child of a 31 year old mother and a 38 year old father. The three older sibs of the patient were normal and healthy.

Birth weight was $2620 \mathrm{~g}$, height $49 \mathrm{~cm}$, and head circumference $33 \mathrm{~cm}$. The following abnormalities were observed: coloboma of the iris (fig 1), bilateral preauricular pits, anal atresia, and bilateral cryptorchidism. Surgery was carried out during the first 24 hours after birth to resolve the anal atresia. The following day he developed a necrotising enterocolitis that was treated medically. Thereafter oral feeding became impossible because of intestinal obstruction. Biopsy of the duodenum, ileum, caecal appendix, sigmoid colon, and rectum showed absence of parasympathetic ganglion cells. The child died at three months of age; this was attributed to sepsis related to a central catheter for parenteral hyperalimentation.

\section{CYTOGENETIC STUDIES}

Cytogenetic studies on peripheral blood cells of the patient showed 47 chromosomes in all cells, with a supernumerary chromosome smaller than a G chromosome (fig 2). The karyotype of both parents was normal."

\section{Discussion}

Our diagnosis was made according to the minimal clinical criteria of Hsu and Hirschhorn, ${ }^{2}$ in that our patient had a combination of two major features, coloboma of the iris and anal atresia, plus one of the most frequent associated anomalies, preauricular pits. Also, the cytogenetic results in lymphocytes using $G$ banding showed a small supernumerary chromosome shorter than a 22 .

The outstanding feature in this case is the absence of parasympathetic ganglion cells throughout the intestinal tract. To our knowledge this is the first case of cat eye syndrome associated with a complete absence of ganglion cells in the large and small intestine. However, this association may be coincidental.

\footnotetext{
References

1 McDermid H, Duncan A, Brasch K, et al. Characterization of the supernumerary chromosome in cat eye syndrome. Science 1986;232:646-8.

${ }^{2}$ Hsu L, Hirschhorn K. Trisomy 22 syndrome and the cat eye syndrome. In: Yunis J, ed. New chromosomal syndromes. New York, San Francisco, London: Academic Press, 1977:339-68.
}

Correspondence to Dr John Ward, PO Box 10-378, Zona 4, Panamá, Panamá.

\title{
A single maxillary incisor as a manifestation of an ectodermal dysplasia
}

\author{
INGE BUNTINX* AND MICHAEL BARAITSER $†$ \\ ${ }^{*}$ Department of Medical Genetics, Universitaire Instelling Antwerpen, Universiteitsplein, 2610 Wilryk, \\ Belgium; and †Hospitals for Sick Children, Great Ormond Street, London WC1N 3JH.
}

SUMMARY A single, central, maxillary incisor was found in a patient with an ectodermal dysplasia.

Received for publication 17 January 1989.

Revised version accepted for publication 17 May 1989.
Clinical geneticists continue to encounter new types of ectodermal dysplasia each with its own mode of inheritance. The problem is that precise identification is essential for appropriate genetic counselling. We present two sibs with an abnormality of hair, nails, and teeth in which the dental anomaly in one of the 


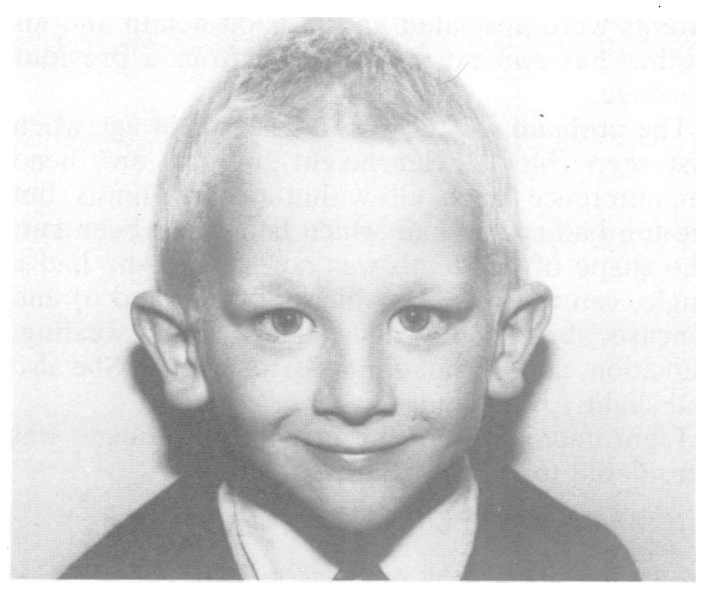

FIG 1 Proband. Note sparse hair, lack of eyebrows, and prominent ears. affected sibs is represented by the presence of a single, central incisor. Although this is an unusual manifestation, it should be considered as significant in possible gene carriers, as has been alluded to by Winter $e^{a} \mathrm{al}^{1}$ in a family with dominant inheritance. In the family presented here, the inheritance pattern is likely to be autosomal recessive.

\section{Case report}

The proband is a five year old boy who presented with the following features. He had sparse, very slow growing hair, small, widely spaced, cone shaped teeth (none seemed to be missing), and concave, dysplastic nails (figs 1 to 3 ). The nails on his feet were more affected than those on his hands. Sweating and salivation were normal although tear secretion was not copious. He had no other cutaneous manifestations and he was of normal

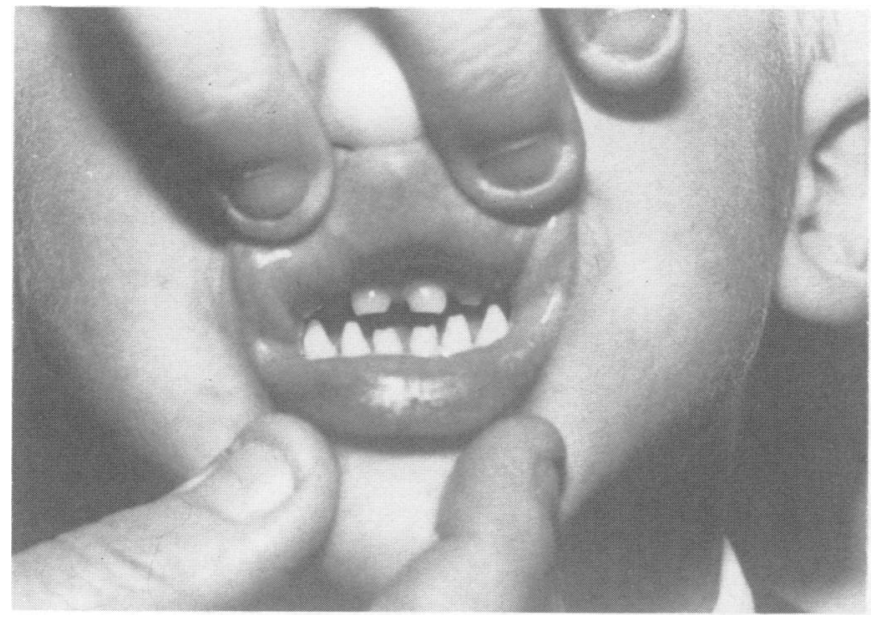

FIG 2 Cone shaped teeth of proband.

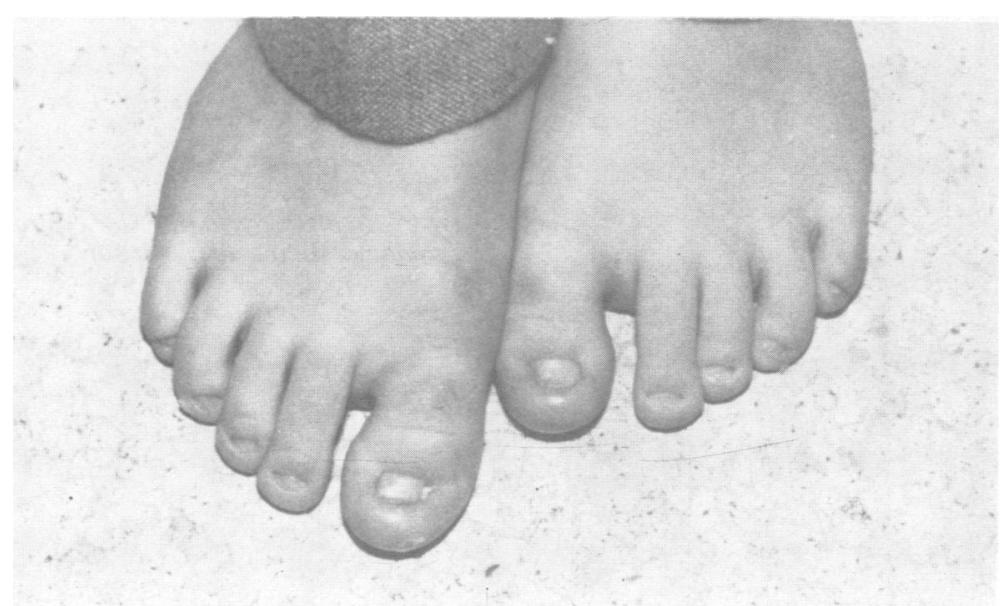

FIG 3 Dysplasticnailsof proband. 


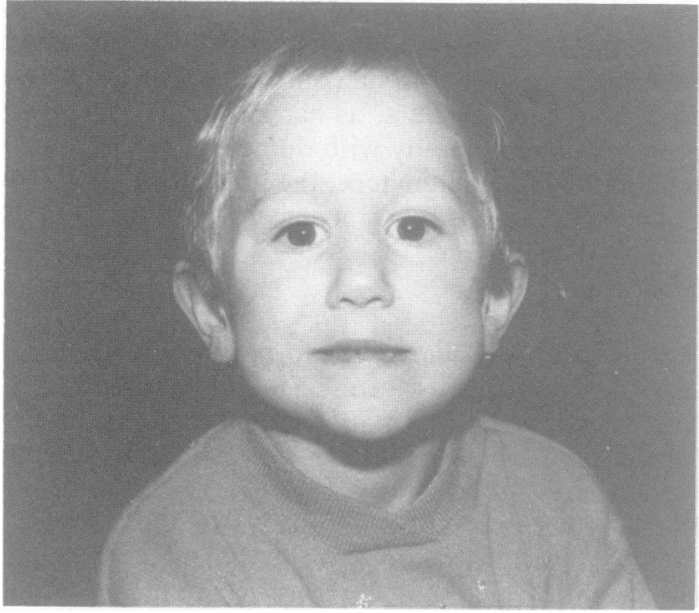

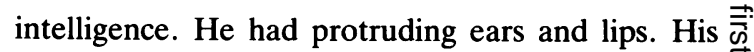
parents were unrelated and in good health and his mother has two normal children from a previous marriage.

The proband's sister was three years of age when first seen (fig 4). Her height, weight, and head circumference were all within normal limits but she too had sparse hair which had never been cut. The shape of her teeth was normal but she had a single, central, maxillary incisor (figs 5 and 6) and concave, brittle toe nails. Her skin, sweating, salivation, and lacrimation were all normal. She also had slightly protruding ears.

Light microscopy of the hair in the proband was considered to be normal.

FIG 4 Proband's sister. Note sparse hair.

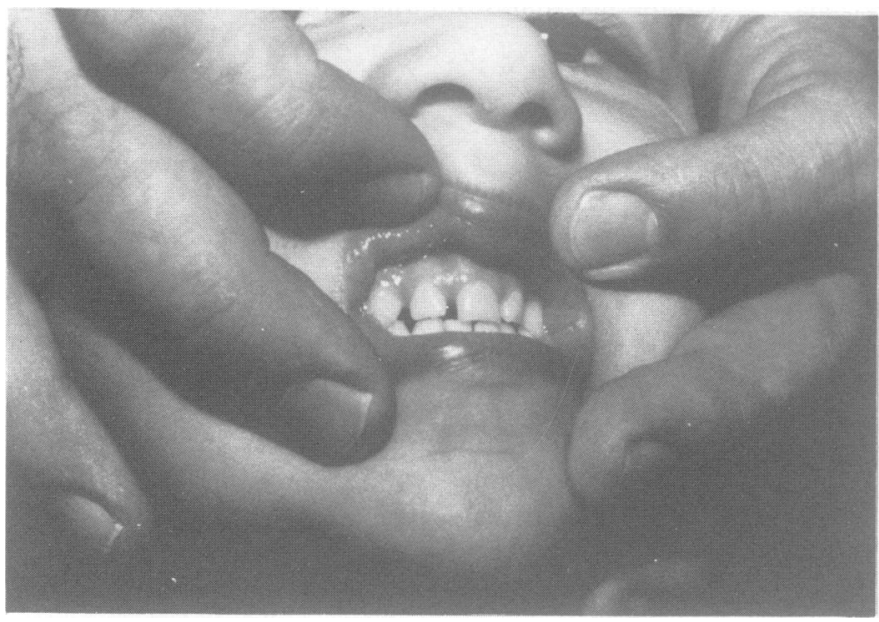

FIG 5 Sister's single, central, maxillary incisor.

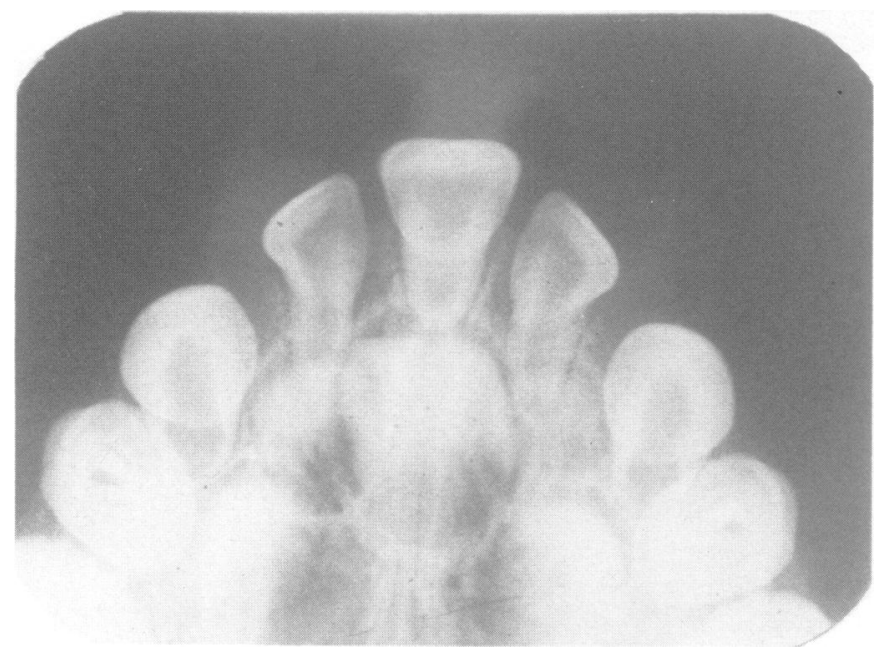

FIG 6 Dental $x$ ray to show the central position of the maxillary incisor. 


\section{Discussion}

A single, central, maxillary incisor is known to be a feature of a few conditions. The best known is its association with holoprosencephaly, ${ }^{2}$ in which children have an undivided forebrain, either partial or complete, and almost always associated with severe retardation. Most cases are sporadic but some are chromosomal and, very occasionally, there is a dominant pattern of transmission. Some gene carriers may have only the tooth abnormality and normal intelligence, but this is rare. A single, central, upper incisor has also been found in association with precocious puberty and hypothalamic hamartoma ${ }^{3}$ and in patients with short stature, some of whom show growth hormone deficiency. ${ }^{4}$ The sister of the proband in our case had a single, normally formed, central, maxillary incisor as part of the ectodermal dysplasia. The dental $x$ ray (fig 6 ) clearly shows the tooth to be midline in origin.

The condition reported by Winter et al ${ }^{1}$ showed

TABLE Clinical manifestations in this and similar families.

\begin{tabular}{|c|c|c|c|c|c|}
\hline & Proband & Sister & $\begin{array}{l}\text { Winter } \\
\text { et al }\end{array}$ & Fried $^{7}$ & $\begin{array}{l}\text { Witkop } \\
\text { et at }\end{array}$ \\
\hline Sparse hair & + & + & + & + & + \\
\hline Scanty eyebrows & + & + & + & + & + \\
\hline Brittle nails & + & + & + & + & + \\
\hline $\begin{array}{l}\text { Single. central, } \\
\text { maxillary incisor }\end{array}$ & - & + & + & - & - \\
\hline $\begin{array}{l}\text { Other tooth abnormalities } \\
\text { (cone shaped, hypodontia) }\end{array}$ & + & - & - & + & + \\
\hline $\begin{array}{l}\text { Abnormal skin } \\
\text { pigmentation }\end{array}$ & - & - & + & - & - \\
\hline $\begin{array}{l}\text { Hyperkeratosis of } \\
\text { hands/feet }\end{array}$ & - & - & \pm & - & - \\
\hline Reduced tears & + & - & - & - & - \\
\hline Reduced sweating & - & - & - & - & - \\
\hline Short stature & - & - & + & - & - \\
\hline Protruding ears & + & + & + & - & - \\
\hline Cleft lip & - & - & - & + & - \\
\hline Everted lips & + & - & + & + & + \\
\hline Hypoplastic thumbs & - & - & + & - & - \\
\hline Syndactyly of fingers & - & - & + & - & - \\
\hline Inheritance & AR? & AR? & AD & AR & AD \\
\hline
\end{tabular}

some members of a family with an autosomal dominant ectodermal dysplasia to have single, central, maxillary incisors as part of the clinical picture. Their parents had sparse hair, hypoplastic thumbs with dysplastic brittle thumb nails, short stature, and mottled skin pigmentation. Protruding ears were another feature in this family.

The condition in our family has occurred in a single generation and both parents are normal. Freire-Maia and Pinheiro ${ }^{5}$ and Witkop et al ${ }^{6}$ described a condition also called the 'tooth-nail' syndrome which is similar to the sibs in our report, but that too is dominantly inherited and single incisors do not occur. An apparently autosomal recessive form of ectodermal dysplasia has been described by Fried, ${ }^{7}$ but there was, in addition, a cleft lip, branchial cysts, and eversion of the lower lips. These conditions are compared in the table.

In conclusion, we draw attention to the importance of an unusual clinical sign in dysmorphology as a manifestation of a new ectodermal dysplasia.

\section{References}

1 Winter RM, MacDermot KD, Hill FJ. Sparse hair, short stature, hypoplastic thumb, single upper central incisor and abnormal skin pigmentation: a possible new form of ectodermal dysplasia. Am J Med Genet 1988;29:209-16.

2 Berry SA, Pierpoint ME, Gorlin RJ. Single central incisor in familial holoprosencephaly. J Pediatr 1984;104:877-80.

3 Winter WE, Rosenbloom AL, MacLean NK, Mickle PJ. Solitary, central, maxillary incisor associated with precocious puberty and hypothalamic hamartoma. J Pediatr 1982;101:965-7.

4 Rappaport EB, Ulstrom RA, Gorlin RJ, Lucky AW, Colle E, Miser J. Solitary maxillary central incisor and short stature. $J$ Pediatr 1977;91:924-8.

${ }^{5}$ Freire-Maia N, Pinheiro M. Ectodermal dysplasias: a clinical and genetic study. New York: Alan R Liss, 1984:80-2.

6 Witkop CJ Jr, Brearley LJ, Gentry WC. Hypoplastic enamel, onycholysis, and hypohidrosis inherited as autosomal dominant trait. A review of ectodermal dysplasia syndromes. Oral Surg 1975;39:71-86.

${ }^{7}$ Fried K. Autosomal recessive hidrotic ectodermal dysplasia. J Med Genet 1977;14:137-9.

Correspondence to Dr M Baraitser, Department of Clinical Genetics, The Hospitals for Sick Children, Great Ormond Street, London WC1N 3JH. 